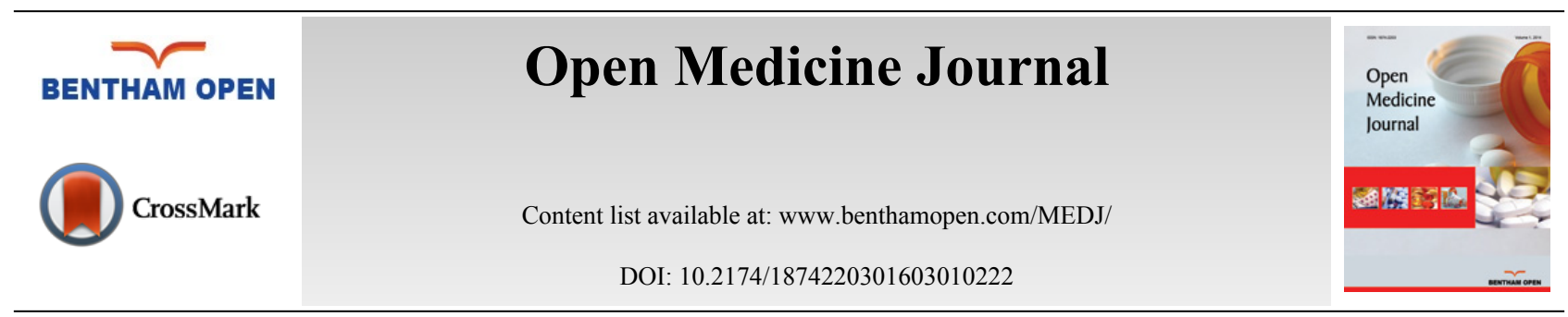

REVIEW ARTICLE

\title{
Forensic Nursing Education: Online Programs
}

\author{
Paul Thomas Clements ${ }^{*}$
}

Forensic Trends in Healthcare Certificate Program Online Distinguished Fellow - International Association of Forensic Nurses, Drexel University - College of Nursing and Health Professions, 1601 Cherry Street, MS 91046 , Philadelphia, Pa 19102, United States

\begin{abstract}
The shift to online forensic nursing education is growing in professional development and continuing education required for certification. Students and instructors are attracted by the ease of use and personalization inherent to asynchronous online instruction. Online education can provide a mechanism for timely and supplemental training to address personnel shortages in certain professional roles, such as forensic nursing. Since all students will necessarily be adult learners, and already possessing professional licensure, they will bring with them a wide array of experience from the forensic arena, ranging from entrée into the field to having years in the trenches. It is imperative that all students, from novice to expert, establish a sense of comfort to safely demonstrate their current level of expertise and knowledge. Based on the virtual exponential explosion of advances in technology for educational settings, the path to learning will be ever changing. As this occurs, educational strategies from forensic nursing instructors must be pedagogically translated for the learner who must simultaneously navigate the responsibilities of home, work and school, and will necessarily need to continue to facilitate not only flexibility of learning, but simultaneously maximize immediate utilization in the real world of forensic nursing practice.
\end{abstract}

Keywords: Forensic, Nursing education, Online programs, Professional development.

\section{INTRODUCTION}

The shift to online education is growing not only in the formal education system, but also in professional development and continuing education required for certification. Students and instructors are attracted by the ease of use and personalization inherent to asynchronous online instruction. Online education continues to expand access (by learner life stage, geography, and time commitment) and, of note, a Sloan-C study expects most of the growth to occur within large institutions that already have existing online offerings and experience in the field [1]. This prediction is congruent with the proliferation over the past decade of graduate degrees and concentrations in forensic nursing. Additionally, certificate programs, such as those in forensic nursing, were recently described as The 'New Black' in Professional Development, noting a time when employers and employees alike are increasingly focused on maximizing their return on training and tuition investment [2]. Despite quality concerns about student learning and diploma mills, a 2003 Sloan survey found that 57 percent of academic leaders rated the learning outcomes in online education as the same or superior to those in face-to-face. That number is now 62 percent, a small but noteworthy increase [1].

\section{ONLINE EDUCATION}

Online education can provide a mechanism for timely and supplemental training to address personnel shortages in certain professional roles, such as forensic nursing. For example, according to the International Association of Forensic Nurses [3]:

"Victims of violence and abuse require care from a health professional who is trained to treat the trauma associated

\footnotetext{
* Address correspondence to this author at the Drexel University - College of Nursing and Health Professions, 109 Trumpet Lane Asheville, Nc 28803-8677, United States; Tel: +828-654-0006; E-mail: paul.thomas.clements@drexel.edu
} 
with the wrong that has been done to them-be it sexual assault, intimate partner violence, neglect, or other forms of intentional injury. Forensic nurses are also a critical resource for anti-violence efforts. They collect evidence and give testimony that can be used in a court of law to apprehend or prosecute perpetrators who commit violent and abusive acts. By hiring and educating Forensic Nurses, communities supply themselves with a vital link to the administration of justice" [4].

Further, Vice-President Joe Biden reinforced this assertion within the national spotlight with his avid and very public support of forensic nurses, formally stating that "Forensic Nurses play an integral role in bridging the gap between law and medicine. They should be in each and every emergency room" [4].

Distance education is a formal learning activity, which occurs when students and instructors are separated by geographic distance or by time. Learning is supported by communications technology such as computers, tablets, smart phones, e-mail, synchronous meeting software (SKYPE, Zoom, Facetime, etc) and a variety of learning management systems (LMS). Online learning is any learning experience or environment that relies upon the Internet/World Wide Web (WWW or Web) as the primary delivery mode of communication and presentation. There are many potential benefits of investing in online learning; for example, increased access, flexibility for both student and instructor, improved quality of learning, better preparation of students for a knowledge-based society, lifelong learning opportunity, profit making, and many more [5,6]. With the growing zest for interactive, collaborative, dynamic, and relevant instruction, there is something significant happening in learning environments today across every educational level and sector, including forensic nursing. Simply put, the creation of learning materials is no longer the sole province of the instructor, instructional designer, or some other educational expert. In this new age of learning, everyone can contribute something to the palette of course materials and resources [6], including those teaching in the forensic sciences.

The Web 2.0 approach tilts the balance of power in the classroom toward those doing the learning. They no longer have to passively consume or browse through available contents; now, they can add to them [6]. As Brown and Adler [7] contend, learners' minds are now on fire as they discover and create new information and then reveal it to others. To emphasize the learning possibilities in the virtual classroom, at times the internet is referred to the Web of Learning. This Web of Learning brings a rich tapestry of learning possibilities to each connected citizen of this planet. The Web of Learning metaphor reminds those teaching and learning online of the thousands or perhaps millions of interconnected learning-related uses of online resources and technologies [8]. In effect, it expands the confines of traditional classroom learning by empowering learners to draw from experience, engage in flexible yet active learning and develop active social networks with peers within the forensic nursing realm.

Learning now resides within everyone's reach. The flexibility of virtual environments allows for ease of access to the most contemporary and cutting edge forensic nursing information, including bringing in experts to their classes for real-time discussions, as well as asynchronous ones, including from remote parts of the nation (or the world), facilitating interaction and collaboration with forensic nursing peers and mentors. The classroom without walls can result in curiosity being piqued, learning being exciting, and feedback being enhanced [9]. There is an authentic audience to interact with that extends beyond the instructor or online course system; specifically, via virtual learning environments, the motivational level of learners can be elevated several degrees [6 - 8]. When in such a setting, mobile devices can call up pertinent information that is contextually based, thereby filling in the gaps in one's knowledge and accelerating personal growth within a field of study. Today, resources are often just one click away and can be quickly accessed and explored.

Without a doubt, this is a new learning age. We are in the "Learning Century" [6] however, Bonk and Khoo [6], pioneers in identifying foundational underpinnings of successful virtual learning environments, note that despite the plethora of ways to learn today, most online courses remain caught up in old expectations of how a course is conducted. There are captured lectures to watch and articles or e-books to read prior to unit quizzes and summative examinations. Such courses remain firmly rooted in a text-centered past. They further highlight this challenging situation by describing:

"A joke often heard at the dawn of online learning was that some institutions and organizations were giving certificates and degrees in electronic page turning. Suffice it to say, in the age of the Web 2.0, such an approach is definitely not a laughing matter. It is no small wonder why students spurn such dreary classes in favor of those that are more in keeping with the times" [6].

Bonk and Khoo [6], after much research and examination, developed The TEC-VARIETY framework to enhance 
virtual learning environments. The framework purposely takes into account current technology trends and attempts to stimulate their use in pedagogically effective ways. As such, it rests at the intersection of such exciting educational affordances brought about by emerging learning technologies, intrinsic as well as extrinsic motivation-related theories, and the rapidly shifting perspectives on teaching and learning philosophies and approaches [6].

Using the TEC-VARIETY method (Tone, Encouragement, Curiosity - Variety, Autonomy, Relevance, Interactivity, Engagement, Tension, Controversy, Yielding Products) as a template, each facet, as it relates toward constructing forensic nursing education in the virtual setting, is reviewed and adapted below.

\section{TEC-VARIETY AND ONLINE FORENSIC NURSING EDUCATION}

\section{Tone/Climate}

The initial facet of establishing the virtual learning environment includes providing for Psychological Safety, Comfort, and Sense of Belonging. These factors are of significance in any classroom setting, however, establishing these foundations in a forensic nursing education environment is paramount. Since all students will necessarily be adult learners, and already possessing professional licensure, they will bring with them a wide array of experience from the forensic arena, ranging from being a novice to years in the trenches. It is imperative that all students, from novice to expert, establish a sense of comfort to safely demonstrate their current level of expertise and knowledge without feeling embarrassed or judged. Regardless of experience and expertise, there is an opportunity to learn. When it comes to establishing a certain tone and climate, there are many methods to facilitate development of a sense of community for the course ahead. For example, one powerful and generally easy method is a self-introduction. During the first 2-3 days of the course, in a designated Discussion Board, each student will provide information about themselves while simultaneously learning about the others in the class. To enhance the learning about each other, the following information is provided as one example to guide the "getting to know you " process:

Please share your name and your geographic location.

What was your interest in taking this forensic course?

Please share what experience, if any, you have in the area of forensic nursing.

What do you hope to learn in this course?

Lastly, please feel free to share anything else you would like your peers and the instructor to know.

Clearly, these questions can be tailored to gather the information that each individual instructor will find most helpful - particularly as each cohort of students will have its own unique dynamics and will develop its own identity and sense of community. This initial introduction discussion board can immediately promote identification of commonalities among peers, begin the formation of peer-to-peer relationships, and most notably, this provides an overarching view, for the instructor, of the initial culture and composition of the cohort of students for the course.

\section{Encouragement}

Now that introductions have been established, it is immediately important for the instructor to establish the tone for the learning environment for the course. Each instructor does, indeed, have his or her own unique online teaching style and pedagogical philosophy. Subsequently, this is the time to provide this overarching view to the students. Foundational facets for this phase include approaches relative to Feedback, Responsiveness, Praise, and Supports. Given the inherent nature of online learning - specifically, that there is flexibility in access, geographic location, allowance for personal schedules and learning patterns - encouragement and feedback are often asynchronous in nature.

Research on virtual learning clearly indicates that one of the most foundational factors for successful online education is communication $[10,11]$. Students are often anxious regarding their performance throughout the course; many end-of-course evaluations acknowledge this by asking a question similar to "I knew where I stood in the course at all times throughout the semester." This can be particularly true in forensic nursing courses given the sensitive nature of the content, but additionally the medico-legal implications that mastery of the information will have on each student's own forensic practice. Students benefit from and appreciate the instructor posting class-wide announcements in the course shell or via group e-mail that include information on recent student performances. As should be standard for all online instructors, posting of comments and observations in scheduled and scored discussion forums can provide important information to all students simultaneously; in fact, this might be the most frequent method of feedback that 
will be used. Depending on the structure of the course, individual feedback may accompany the scoring for each Discussion Board or module. Feedback from peers, who also may more extensive expertise and experience with the topic being discussed in a particular module, can be very useful for both novices as well as for other seasoned peers. This also can provide for a sense of collegiality and promote working collaboratively and synergistically versus the frustrating silo healthcare approach [12] that can often result in fragmented forensic care across the interdisciplinary medico-legal continuum.

\section{Curiosity}

Curiosity is often a very powerful driving force for learning and includes Surprise, Intrigue, and Unknowns. There are many ways to enhance these facets in the online learning environment and the impact on learner engagement can be significant. Online learning allows for quick access of information from one click of the mouse to the next. The thoughtful combination of audio and video streaming can stimulate the senses, and thus enhance learner curiosity. One example can include scanning daily events in the mainstream media regarding a current forensic case with the search for foundational information relative to the underlying dynamics and evidence, analysis of the forensic implications of progressive evolution of the case, and even the impact of media portrayal by various journalistic sources. The case may be national or even local since access of information is not limited by virtue of geography.

Another example may involve searching for information, as assigned by the instructor, that results in a tour of a national resource agency that can be very useful when working with forensic cases in the real world setting; this could include the Department of Justice (DOJ), Federal Bureau of Investigation (FBI), the Rape, Abuse and Incest National Network (RAINN), the National Center for Missing and Exploited Children (NCMEC), the International Association of Forensic Nurses (IAFN) etc.

Another example of providing curiosity and intrigue within a forensic nursing course is assigning each student to locate their particular State Sexual Offender Registry and learning to use the search function to determine the number of registered offenders living within 5 miles of their own home. Subsequently, each student will report back to the class, in a designated Discussion Board, detailing their findings of what information the registry provides, their thoughts about how the registry might be used by forensic practitioners to promote safety for children and families, and their thoughts on the ethics versus benefits of such registries (i.e., are offenders being punished twice by being exposed to the public?). This exercise is one example of how using an interactive database can enhance interest and engagement into the course content, expand the ability to navigate current technological resources, gather relevant information, and translate findings toward enhancing clinical forensic practice.

\section{Variety}

It is generally acknowledged that learners expect virtual courses to have bells and whistles - meaning that with the wide variety of technological resources, that online learning should inherently be multidimensional and include multimedia approaches. Variety in online learning should necessarily include Novelty, Fun, and Fantasy. In contemporary virtual learning environments, the constructivist philosophy has become quite common. This has been embodied by describing online instructors as no longer being the sage on the stage but rather the guide on the side [13]. It is suggested that constructivist teaching is a better fit for content that requires problem solving and critical thinking skills such as in forensic nursing courses. That being said, virtually all content teaching needs to start out with a direct instructional approach and move towards a constructivist approach. In other words, instructors generally need to provide a more direct instructional approach in the beginning, and then slowly pass the responsibility of learning over to the students [13].

To enhance understanding of the course objectives, it is important to avoid a traditional lecture - learner approach to disseminating content. In light of the wide array of technological options, it is possible to facilitate a multimodal approach to providing content. Case Studies are one example. Case studies have been described as having the capacity to make the information come alive and have translation to the real world. A well-crafted case scenario "may be especially appropriate for developing higher-order intellectual skills such as analysis, synthesis, and evaluation...cases also help trainees develop the willingness to take risks given uncertain outcomes, based on their analysis of the situation" [14].

Interactive simulations are another method that provide for fun ways of learning forensic nursing content, such as creating a virtual crime scene, allowing students to determine risk factors that may have increased the potential for the violence, and translating that information to patient safety promotion education. Educational videos, many of which are 
available from YouTube, can provide for visual learning. Some examples may include video presentations on the purpose and role of the forensic autopsy, the foundational approaches to forensic toxicology, or the impact of DNA on forensic cases. Instructors will find that the World Wide Web now provides for a wide array of educational materials that are a part of the public domain.

\section{Autonomy}

Opportunities to choose and to act on their learning choices can have a powerful influence on learner satisfaction and performance. It can result in a feeling of increased autonomy enhances intrinsic motivation and offers learners a sense of control over their learning situation [15]. To promote this sense of autonomy, forensic nursing courses should include considerations regarding Choice, Control, Flexibility, and Opportunities.

Flexibility and variety let students exercise more control over the choices they make in a class. This can make assignments more engaging. Providing multiple options for completing assignments is one way to introduce flexibility; specifically, designing assignments that allow for multiple types of answers or learning approaches [16]. Research has noted the importance of engaging students early in the course; specifically, introducing interesting, provocative assignments early in the course draw students in, habituate them to the kinds of coursework planned, and engage them actively in the larger course community. Further, assignments which provide for choice while meeting the foundational objectives of the assignment, tend to engage students into the course and content, particularly if established early in the course and requiring planning and preparation [16].

One example that provides for autonomous selection includes assigning students to attend a session of court. This assignment can be quite an adventure, particularly in light of the typical perceptions (or, more accurately, misperceptions) of court proceedings - envisioning that these are similar to television depictions such as Judge Judy or The Peoples Court. Additionally, congruent with contemporary research, on what is now called the CSI Effect, it has been demonstrated that there is an impact on jurors and difficulty with reaching a verdict based on the lack of what has become (yet, erroneously) perceived to be necessary forms of evidence (i.e. elaborate forensic testing with unique and high specificity). For example, in one case study, a juror noted his ethical reservations to convict the defendant because "they did not even test the lawn for fingerprints" [17]. Attending court can be a profoundly revealing experience regarding everything from the arrest, to the voir dire process and jury selection, the importance of accurate and objective medico-legal documentation, the roles of the prosecuting and defense attorneys and notably, and the role of the expert forensic witness. The assignment allows for flexibility and individualization by allowing each student to select the form of court proceedings that is of interest based on the focus of their own forensic professional practice and goals. This can be District or Federal court, Family court (which typically requires previous permission via phone call, but is usually easily attained), mental health court, or Municipal court. The trial can be criminal or civil in nature. Students then compose a report regarding various required facets. A few examples might include:

Describing the planning and journey to get to the courthouse and finding the case/cases to observe.

Was it easy to navigate within the courthouse?

The type of case that was observed and courtroom setting

The courtroom environment

What did you observe about the process in the courtroom?

The personal thoughts and perceptions you had during the field exercise.

Clearly, the scripted questions can be tailored by the instructor to target the focus of the experiential assignment.

\section{Relevance}

All learning should be relevant. It should be Meaningful, Authentic, and Interesting. When constructing courses for clinically based education, such as forensic nursing, key and take away points and practices are of significant importance. The instructor should be mindful that the information being provided and the assignments that are required should provide for translation to enhance, modify, or extend clinical forensic nursing practice. Effective adaptation to real life situations or to the real world of forensic nursing will be of paramount interest to learners. This is partially addressed during the Tone/Climate facet, when students are asked what they expect to learn from the particular course. 


\section{Interactivity}

Interactivity in online courses includes the facets of being Collaborative, Team-Based, and Community involvement. Moore [18] proposed three key types of interactivity: (1) learner interaction with content or the subject of study, (2) learner interaction with other learners with or without the instructor, and (3) learner interaction with an instructor or other experts assuming the role of instructor.

For example, one assignment may involve conceptualizing, and constructing a Community Safety Promotion/Victim Reduction Project that will be implemented in a local community of the student's choice. This, in essence, flips the classroom and allows the student to become the expert, the instructor, with the community becoming the new learners [19]. During week one, to immediately promote engagement in the course, each student will have the opportunity to select a forensic topic of interest that they would like to research in depth; something that will advance their own forensic knowledge as well as provide a public service of education to a target group in their community. There is a broad array of potential project topics related to safety promotion, victim reduction, violence prevention. For example, topics may include: preventing date rape, preventing crimes against the elderly such as telemarketing schemes, recognizing child abuse, hospital based workplace safety, teaching stranger safety to children, development of a crime watch with neighbors, teaching children about dialing 9-1-1, etc. Students then report back, typically in a written paper assignment, regarding the entire process from conceptualization, preparation, planning, implementation and evaluation. This assignment directly addresses each of the three facets of interactivity as described above [18].

\section{Engagement}

It has been suggested that engagement is made up of three variables: (1) deep attention to the learning task or situation; (2) the activation of effective cognitive processes (e.g., strategies of rehearsal, organization, visual imagery, monitoring comprehension, and so on); and (3) the social context or community in which learning occurs [20]. This phase of the process additionally includes Effort, Involvement, and Investment.

In online forensic courses, engagement can be facilitated in a variety of ways; typically, the most common approach involves asynchronous discussion boards, which revolve around examination and analysis of information in a topicfocused or case scenario based module. The instructor posts the initial discussion question for the module and then moderates the discussion throughout the assigned time frame for completion. It is important to monitor student engagement and to provide expectations at the beginning of the course. For example, it is important to establish the difference between posting and discussion. Specifically, if the duration of a discussion board is to include a one week period, students who post entirely in the beginning of the week or entirely at the end of the week, are not necessarily engaging in discussion - rather, they are posting their thoughts; however this does not reflect fluidity of scholarly discourse or extension of the discussion based on commentary from peers and the instructor.

Another method of engagement may include a synchronous presentation, a guest lecture from an expert in the content area for that specific module, or a group discussion regarding a previously posted case study. Synchronous sessions provide for a feeling of a live classroom and can provide for a three dimensionality that is not necessarily experienced in asynchronous discussion boards. Attempting to utilize synchronous discussions throughout the course would be akin to recreating the face to face classroom, albeit electronically, and can be quite challenging to maintain based on varying geographic time zones, as well as student and instructor schedules. Rather, a combination of methods allows for more flexibility of student schedule and preferred learning approach, which are alluring factors for online learners.

\section{Tension}

Promoting tension in the virtual forensic nursing classroom could initially seem counterintuitive, however, the use of Challenge, Dissonance, and Controversy can provide for in-depth analysis and examination of implications for clinical forensic practice relative to a variety of situations, scenarios or philosophical underpinnings.

Online discussion forums can often address controversial issues and result in strong learner interactions, reactions and debates; this can be particularly true for forensic nursing content. There can be passionate commentary during asynchronous discussions among students, which can provide a forum to hone the art of scholarly and professional discourse. There are many other methods available to arouse learner tension and curiosity. For example, given the barometer of extremely varying views, as portrayed by the media, regarding high profile crimes and violence, using a current case to encourage examination of a targeted question by the instructor, can provide for a real time analysis of a 
real world forensic situation.

Another example is thoughtfully posing a controversial question to students in discussion boards, which can result in intense examination of research, facts, myths and stereotypes, and varying professional philosophies regarding victims or alleged offenders of interpersonal violence and crime. Specifically, in a course that will be examining the theory, research and practice with victims of violence, the initial Discussion Board could revolve around the primary post of " Can victims of violence ever truly recover? " Similarly, in a course that will focus on the medico-legal interface with convicted offenders of interpersonal violence, the primary post of "Can offenders ever truly be rehabilitated?" typically sparks a variety of views and leads toward examination of many faceted viewpoints. In both situations, the discussions often result in some highly charged professional (and personal) opinions and perceptions, which then allows the instructor to require students to go to the existing scholarly literature to gather additional information and to provide supportive citations to contextualize their stance. Often, these controversial and tensionproducing discussions promote students to examine and, at times, challenge their own views and beliefs, as well as requiring them to hone their skills of engagement with professional peers regarding differing views and practice approaches.

Another example is having students watch a media presentation then the instructor posits a thought provoking initial post regarding the situation. YouTube is an often overlooked resource for educational videos. This could, for example, include a special journalistic report on a contemporary crime that has a variety of potential views and implications. One such report included a four-part documentary produced by the American Broadcasting System (ABC) regarding the controversial case of Alex Kelly. Kelly was charged with committing two rapes within a four-day period in Darien, Connecticut. The videos include interviews with Alex Kelly, his parents, his lawyer and his fiancée and provide for much tension and dissension among students regarding the views of his behavior, his parents' actions and the strategies by the attorney to procure his release. Other YouTube productions include interviews with convicted murders, serial killers, rapists, registered sexual offenders and arsonists, many of whom clearly demonstrate psychopathology in their commentary and perceptions, which provides for analysis and robust discussion by students during a particular educational module.

\section{Yielding Products}

"When you involve learners in forms of learning based on products, projects, cases, or problems, you incentivize the system" [6]. The final facet of online learning includes that the course is Goal Driven, provides for a Purposeful Vision, and provides for Ownership. "Goals alone will not determine success; to achieve success, goals must be realistic and valued. When learners have some prior experience or knowledge in an area, they can be pushed to accomplish a more challenging target. Offering learners alternative choices in their course projects is one way to clear such a path" [6]. A learner might find such a passion in one of the self-directed course experiences or assignments that they will enhance or modify their current practice with new approaches to clinical forensic care. Others may work with management or administration to create or modify policy related to assessment and intervention with victims or offenders in their healthcare facility. Others might develop educational offerings for employees or safety promotion materials for patients. When a student can simultaneously learn new forensic nursing knowledge and immediately translate that information toward enhancing or extending their clinical practice, a sense of ownership, mastery and satisfaction can be attained.

\section{CONCLUSION}

The Web of Learning continues to expand and evolve and will continue to increase in attraction to instructors and learners. Based on the virtual exponential explosion of advances in technology for educational settings, the path to learning will be ever changing. As this occurs, educational strategies, for the learner who must simultaneously juggle the responsibilities of home, work and school, will necessarily need to continue to facilitate not only flexibility of learning, but simultaneously maximize immediate utilization in the real world of forensic nursing practice.

\section{CONFLICT OF INTEREST}

The author confirms that this article content has no conflict of interest.

\section{ACKNOWLEDGEMENTS}

Declared none. 


\section{REFERENCES}

[1] Allen IE, Seaman J. Online learning consortium. Staying The Course - Online Education in the United States 2008. Available from: http://www.onlinelearningsurvey.com/reports/staying-the-course.pdf

[2] Aldridge SA. Certificate programs: The "New Black" in professional development. The evolllution. Available from: http://evolllution. com/opinions/certificate-programs-new-black-professional-development/

[3] International Association of Forensic Nurses [IAFN]. What is forensic nursing? Available from: Available from: http:// www.forensicnurses.org/?page=WhatisFN 2015.

[4] Hammer RM, Moynihan B, Pagliaro RM. Forensic nursing: A Handbook for practice. 2nd ed. US: Jones \& Bartlett Learning 2006.

[5] Appana S. A Review of benefits and limitations of online learning in the context of the student, the Instructor and the tenured faculty. Int J ELearn 2008; 7(1): 5-22.

[6] Bonk CJ, Khoo E. Adding Some TEC-VARIETY :100+ Activities for Motivating and Retaining Learners Online. Open World Books, Bloomington, Indiana 2014. Available from: http://tec-variety.com/TEC-Variety_eBook_5-4.pdf

[7] Brown JS, Adler RP. Minds on fire: Open education, the long tail, and learning 2.0. EDUCAUSE Rev 2008; 43(1): 16-32.

[8] Bonk CJ. The World Is Open: How Web Technology Is Revolutionizing Education. San Francisco, CA: Jossey-Bass 2009.

[9] Rodrigues S. A Classroom without Walls Virtual Learning Experiences in Science. In: B France and V Compton Bringing Communities: Connecting Learners with Scientists or Technologists Together. Boston, MA: Sense Publishers 2012; pp. 61-72. [http://dx.doi.org/10.1007/978-94-6091-791-2_4]

[10] Swan K. Building Learning Communities in Online Courses: The importance of interaction. Educ Commun Inf 2002; 2(1): 23-39. [http://dx.doi.org/10.1080/1463631022000005016]

[11] Venable M. The 7 Cs of Effective Communication in Your Online Course. Available from: http://www.onlinecollege.org /2011/09/16/the-7cs-of-effective-communication-in-your-online-course/ 2011.

[12] Newhouse RP, Spring B. Interdisciplinary evidence-based practice: moving from silos to synergy. Nurs Outlook 2010; 58(6): 309-17. [http://dx.doi.org/10.1016/j.outlook.2010.09.001] [PMID: 21074648]

[13] Morris LV, Xu H, Finnegan CL. Roles of faculty in Teaching Asynchronous Online Course. Journal of Asynchronous Learning Networks: A publication of the Sloan Consortium 2005. Available from: http://www.adesignmedia.com/onlineresearch/rolesof\%20facultyundergrad.htm

[14] Noe RA. Employee training and development. $6^{\text {th }}$ ed. New York: McGraw-Hill Irwin 2013.

[15] Pink DH. Drive: The surprising truth about what motivates us. New York, NY: Riverhead Books 2011.

[16] Brown University Characteristics of effective online assignments. Available from: http://www.brown.edu/about/administration /sheridancenter/teaching-learning/course-design/learning-technology/online-assignments 2015.

[17] Shelton DE. The 'CSI Effect': Does It Really Exist? National Institute of Justice: Office of Justice Programs. Available from: http://www.nij.gov/journals/259/pages/csi-effect.aspx 2008.

[18] Moore MG. Editorial: Three types of interactivity. Am J Distance Educ 1989; 3(2): 1-7. [http://dx.doi.org/10.1080/08923648909526659]

[19] Berrett D. How 'Flipping' the Classroom Can Improve the Traditional Lecture. The Chronicle of Higher Education. Available from: http://ctl.ok.ubc.ca/_shared/assets/_Flipping_The_Classroom45753.pdf 2012.

[20] Ingram AL. Engagement in online learning communities In: Bourne J, Moore JC, Eds. Elements of quality online education: Engaging communities, Volume 6 in the Sloan-C Series. Needham, MA: Sloan Consortium 2005.

(C) Paul Thomas Clements; Licensee Bentham Open

This is an open access article licensed under the terms of the Creative Commons Attribution-Non-Commercial 4.0 International Public License (CC BY-NC 4.0) (https://creativecommons.org/licenses/by-nc/4.0/legalcode), which permits unrestricted, non-commercial use, distribution and reproduction in any medium, provided the work is properly cited. 